\title{
黑龙江省不同山系狍种群遗传多样性分析
}

\author{
刘艳华，张明海* \\ (东北林业大学 野生动物资源学院, 黑龙江 哈尔滨 150040)
}

\begin{abstract}
摘要: 狍 (Capreolus pygargus) 为我国重要的经济动物, 并且是国家一级保护动物一一东北虎(Panthera tigris altaica) 的主要食物之一。因此, 深入了解狍各个地理单元内种群的遗传变异, 可以为我们制定保护管理策略提供 依据, 进而恢复珍稀濒危物种的野外种群数量。对 32 个不同狍个体 (来自 3 个不同山系) 的线粒体 DNA 控制区 的部分序列进行了测定和群体分析, 发现了 50 个变异位点, 定义了 27 种单倍型, 其单倍型多样性 $(h)$ 平均值为 0.978 、核苷酸多样性 $(\pi)$ 平均值为 0.02260 , 种群总体遗传多样性较高; 在 3 个地理单元的狍种群中, 大兴安岭 地区的狍种群具有较高的遗传多样性, 应予以优先保护。从 Tajima's $D$ 和 Fu \& Li's $D$ 值的估算结果表明, 这 3 个狍种群与中性进化的歧异度相比, 并没有明显的偏离 $(P>0.1)$, 无明显的证据显示这 3 个狍种群间存在很强的平 衡选择。
\end{abstract}

关键词：狍；粪便 DNA； mtDNA 控制区；遗传多样性；黑龙江

中图分类号: Q959.842; Q951.3 文献标识码: A 文章编号: 0254-5853-(2009)02-0113-08

\section{Population Genetic Diversity of Roe Deer (Capreolus pygargus) in Mountains of Heilongjiang Province}

\author{
LIU Yan-hua, ZHANG Ming-hai* \\ (College of Wildlife Resources, Northeast Forest University, Heilongjiang Harbin 150040 China)
}

\begin{abstract}
The roe deer is an animal of economic importance in China and a primary food source of the Amur tiger. Understanding the morphological and molecular variation of geographically isolated roe deer populations is therefore important in establishing conservation strategies. Thirty two samples from three differences geographic regions were sequenced and the populations analysed. Twenty seven haplotypes were identified from 32 sequences of the $460 \mathrm{bp}$ D-loop of mtDNA genome. Fifty sites were found to be polymorphic. The population genetic diversity of roe deer was of higher level as indicated by the following parameters: mean value of haplotype diversity $(h=0.9780)$ and mean value of nucleotide diversity ( $\pi=0.02260$ ). Neither the estimate of Tajima's D nor that of Fu \& Li's D deviated significantly from the neutral selection hypothesis $(P>0.1)$ for the three populations. The result suggests no evidence of strong selective sweeps or balancing selection. Of the three populations, the Great Khinghan Mountains geographic region was shown to have the most nucleotide diversity. To ensure conservation of genetic diversity within this population, we propose a high priority conservation classification.
\end{abstract}

Key words: Roe deer (Capreolus Pygargus); Faecal DNA; mtDNA control region; Genetic diversity; Heilongjiang

狍（Capreolus pygargus）隶属于偶蹄目 (Artiodactyla) 鹿科（Cervidae）狍属(Capreolus)。 狍是东北常见的中型鹿科动物, 常栖息于疏林、灌 从、河谷或沼泽湿地之中(Sheng, 1992)。狍是我国 重要的经济兽类, 具有肉用、皮用和药用价值, 并
且是国家一级保护动物一一东北虎(Panthera tigris altaica)的主要食物之一, 具有较大的经济和生态价 值。因此, 对其进行有效的管理有助于我们更好地 保护东北虎种群, 以增加这一珍稀濒危物种的野外 种群数量。 
物种遗传多样性的丧失将对狍生存带来直接 的不利影响, 可以使物种更加容易灭绝。任何物种, 只有具备了一定的遗传多样性才能抵御自然界中 的各种压力, 否则, 灭绝将是不可避免的。目前, 关于对狍的研究主要集中在生理、生化和生态上的 描述, 以及对狍人工繁殖与驯养等方面的探讨

(Chen \& Xiao, 1991; Wang et al, 2005; Teng et al, 2006 ); 在分子水平上仅对东北狍的分类地位

(Zhang et al, 2005; Xiao et al, 2004) 和线粒体 DNA 序列的多态性（Yang \& Ma, 2004) 进行了研究。 然而, 关于狍种群遗传多样性变化还未见报道。因 此, 本文测定了来自大兴安岭、小兴安岭和完达山 3 个山系的 32 个野生狍线粒体 DNA 控制区的序列, 分析比较了 3 个山系狍种群的遗传变异水平, 以期 为狍的管理和保护提供科学依据。

\section{1 材料与方法}

\section{1 样品采集}

本实验采用非损伤性取样法, 在大兴安岭、小 兴安岭和完达山 3 个山系各设取样点, 分别为 $T Q$ 、 $\mathrm{XQ}$ 和 DFH (图 1), 共采集不同个体狍粪便样品
32 份, 其分布分别为大兴安岭地区 12 份、小兴安 岭地区 6 份、完达山地区 14 份。采集样品时, 多 选择在冬季落雪后, 在狍经常出现的区域内沿其足 迹链寻找粪便, 以保证狍粪便样品的新鲜程度。采 自野外的粪便样品来自狍, 而非其近源的物种, 且 不属于同一个个体是十分重要的。因此, 在采集过 程中通过足迹链与粪便外观对狍与其他动物进行 分辨。而所采得的粪便是否属于同一狍个体，则采 用微卫星多态性位点检测进行鉴别, 以排除来源于 同一个个体的可能性。为了避免样品的污染, 样品 采集时, 应配带一次性手套, 采集到的样品需封装 到塑料袋内, 并要避免损伤粪便颗粒表层, 以保证 目的 DNA 的质量 (Adams et al, 2003)。每个样品 袋中封装一张标记卡, 其上注明采集地的地理坐 标、采集时间以及生境内的食物组成, 并将样品编 号。

\subsection{DNA 提取}

DNA 提取方法参考上海杰美生物公司生产的 《粪便 DNA 提取试剂盒》使用说明并略作改进, 其具体步骤如下: 取一定量的狍粪便放入雉形离心 管内，加入缓冲液，经浴旋振荡使固态物质充分溶

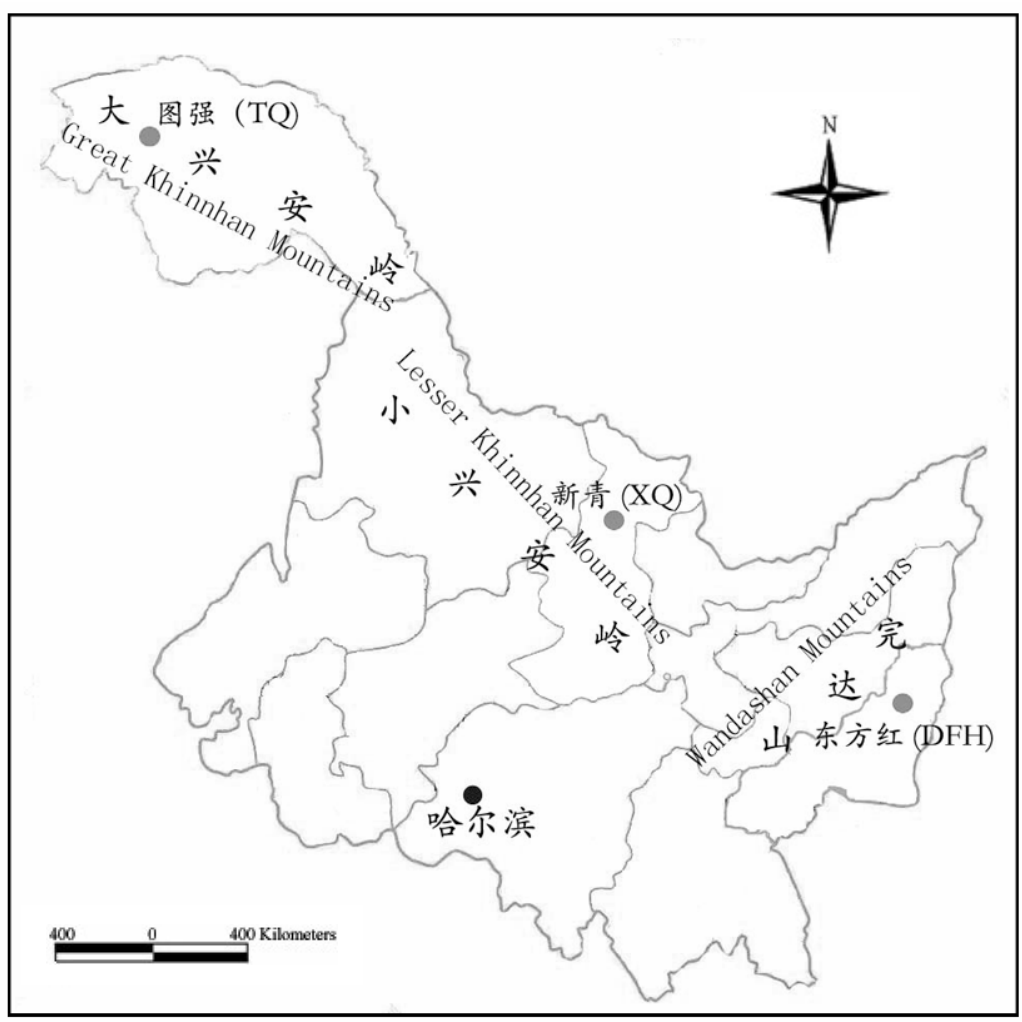

图 1 狍粪便样品采集地

Fig. 1 Geographic location of roe deer faecal sampling in this study 
解, 再经离心处理使杂质沉淀, 然后吸取管内上部 清液。将吸出的上清液放入另一雉形管内, 加入一 定量的酶解液、盐析液和去干扰剂, 经涡旋振荡后 放入培养箱中 $60^{\circ} \mathrm{C}$ 孵育, 使细胞裂解。裂解后的溶 液加入萃取液, 经振荡、离心后, 取上清液放入另 一雉形离心管内; 加入一定量的浓缩液和沉淀液后 再次离心, 去掉上清液; 加入清理液后再次离心, 再次去掉上清液, 将管内物质在空气中自然晾干后 加入保存液, 放入冰箱中 $4^{\circ} \mathrm{C}$ 保存待测。

\subsection{PCR 扩增及其产物的测定}

引物为 L-Pro: 5'-CGTC AGTC TCAC CATC AACC CCCA AAGC-3', H-Phe: 5'-GGGA GACT CATC TAGG CATT TTCA GTG-3' ( Randi \& Pierpaoliand, 1997); 反应体系为 Taq 聚合酶 (Takara)0.3uL, dNTPs(Takara) $5 \mu \mathrm{L}$, BSA(lg/L) $5 \mu \mathrm{L}$, $10 \times$ Buffer $5 \mu \mathrm{L}$, L-Pro 和 H-Phe $(20 \mathrm{mmol} / \mathrm{L})$ 各 0.5 $\mu \mathrm{L}$, DNA100ng, 加灭菌的超纯水至 $50 \mu \mathrm{L}$ 。设计不 加模板的空白对照。反应条件为 $95^{\circ} \mathrm{C}$ 预变性 $10 \mathrm{~min}$; $95^{\circ} \mathrm{C}$ 变性 $30 \mathrm{~s}, 50^{\circ} \mathrm{C}$ 退火 $40 \mathrm{~s}, 72^{\circ} \mathrm{C}$ 延伸 $60 \mathrm{~s}, 40$ 个 循环; 然后 $72^{\circ} \mathrm{C}$ 延伸 $10 \mathrm{~min}, 4^{\circ} \mathrm{C}$ 保存。PCR 产物 采用 $1.0 \%$ 的常规琼脂糖凝胶电泳检测, 上样量为 5 $\mu \mathrm{L}$ PCR 产物加 $1 \mu \mathrm{L} 6 \times$ Loading Buffer, $100 \mathrm{~V}$ 电压 电泳 30min, Good wall 染色, 凝胶成像系统观察电 泳谱带, 并将电泳条带较亮较窄的扩增产物送至上 海生工测序公司进行纯化并测序。

\section{4 序列分析}

序列结果用 Clustal X 软件(Thompson et al, 1997)进行 DNA 序列排列, 并辅以人工校对。用 DnaSP 4.0 软件(Rozas \& Rozas, 2003)计算核苷酸多 样性 (nucleotide diversity, $\pi$ ) 和单倍型多样性 (haplotype diversity, $h$ )。用 MEGA 2.1 软件(Kumar et $\mathrm{al}, 2001)$ 进行序列比较和变异检测, 确定变异位点 和单倍型, 并用距离矩阵邻接法 (neighbor joining, $\mathrm{NJ}$ ）构建系统发育树。用 MrBayes 3.0 (Ronquist \& Huelsenbeck, 2003)软件的贝叶斯法(Bayesian, BI)构 建系统发育树。在构建贝叶斯树时, 共运算 1000000 代, 对每 100 代进行 1 次抽样, 并通过 Modeltest 3.06(Posada \& Crandall, 1998)检验寻找最合适的 DNA 替代模型 $(G T R+I+G)$ 及相关参数, 通过自 引导获得系统树分支的置信值。在构建系统树时, 采用欧洲狍 (Capreolus capreolus) 序列 (GenBank Accession No.: Z70318)作外群, 以获取系统树的根。 用 Arlequin 3.1 软件 (Excoffier \& Smouse, 1999)分
析种群分化系数(Fst)和基因流( $\mathrm{Nm})$ 。

\section{2 结 果}

\subsection{DNA 序列及其差异}

对 32 个狍样本 mtDNA 控制区序列进行测定, 获得了 460bp 的片段, 并检测到 50 个变异位点 (包 括 1 个空隙/缺失位点), 并由此定义了 27 个单倍型 (序列的 GenBank 登录号为: EU122388, FJ416665-FJ416690)。其中 DFH7、DFH8、DFH9 和 DFH11 共享一个单倍型; TQ8 和 TQ11 共享一个 单倍型; XQ1 和 XQ5 共享一个单倍型（表 1)。

\section{2 群体遗传多样性和系统发生关系}

将所测得的 32 个样品 mtDNA D-loop 序列按各 自所属区系归类, 用 DnaSP 软件计算各项遗传变异 参数。从表 2 中可以看出, 大兴安岭种群的遗传多 样性（ $\pi=2.803 \pm 0.225, h=0.985 \pm 0.040 ）$ 高于小 兴安岭 $(\pi=1.946 \pm 0.401, h=0.956 \pm 0.045)$ 和完 达山（ $\pi=1.031 \pm 0.190, h=0.933 \pm 0.122 ）$ 的遗传 多样性。从 Tajima's $D$ 和 Fu \& Li's $D$ 值的估算结果 来看, 这 3 个狍种群与中性进化的歧异度比较并无 明显的偏离 $(P>0.1)$, 没有明显的证据显示这 3 个狍 种群间存在很强的平衡选择(表 2)。

分别对大兴安岭、小兴安岭和完达山 3 个山系 狍种群间遗传关系进行比较, 经分析得出: 大兴安 岭一小兴安岭种群间核苷酸歧异度 $(D x y=0.02537)$ 高于大兴安岭一完达山种群间核苷酸歧异度 $(D x y$ $=0.02336)$ 和小兴安岭一完达山种群间核苷酸歧异 度 $(D x y=0.01762)$, 并根据 Nei（1982）的方法计算 的地理单元间遗传分化系数 (Gauns St) 和根据 Hudson et al (1992)方法计算的地理单元间的基因 流 $(\mathrm{Nm})$ 等值。3 个群体间的遗传分化与基因流见 表 3。

由表 3 可知, 小兴安岭与完达山群体间 Fst 值 为 0.12449 , 两个群体间的每代迁移个体数为 3.53 ( $\Phi s t=0.197, P>0.05)$; 大兴安岭与完达山群体间 Fst 值为 0.20000 , 两个群体间的每代迁移个体数为 2.00 ( $\Phi s t=0.243, P>0.05$ ); 大兴安岭与小兴安岭群 体间 Fst 值为 0.03182 , 两个群体间的每代迁移个体 数为 15.33 ( $\Phi s t=0.145, P>0.05$ )。由此可见大兴安 岭与小兴安岭群体间的分化水平最低, 这两个群体 间的每代迁移个体数最多, 群体间差异均数最低, 说明这两个地理单元间存在着基因流，而大兴安岭 与完达山群体间遗传分化水平最高, 个体迁移数最 
表 127 种狍线粒体 DNA 控制区单倍型序列变异和分布

Tab. 1 Sequence variation and location with $27 \mathrm{mtDNA}$ control region haplotypes in roe deer

\begin{tabular}{|c|c|c|c|c|c|c|}
\hline \multirow{4}{*}{ Haplotype } & \multicolumn{5}{|c|}{ Variable sites } & \multirow{4}{*}{ Location } \\
\hline & 1111 & 1111111111 & 2222222222 & 2222233333 & 3333334444 & \\
\hline & 2440114 & 4456678999 & 2444566778 & 8889911123 & 5566992256 & \\
\hline & 1255124790 & 5907999018 & 3047306070 & 2564912479 & 0201164810 & \\
\hline HT01 & TTTAATTTAG & CGCAAATAAA & CAGCGGAATG & TTAAGATTAT & GGTCCGGTTA & TQ \\
\hline HT02 & $\ldots$ C...... & . A. & $\ldots \ldots \ldots$ & ....... & A. ... A... & DFH \\
\hline HT03 & $\ldots$ & $\cdots$ & $\ldots$ A...... & $\ldots$ A.... & A. ....... & TQ \\
\hline HT04 & . & & ...A.A.... & $\ldots$ T. .... & & TQ \\
\hline HT05 & $\ldots \ldots \ldots$ & $\ldots \ldots \ldots$ & ...A. A.... & $\ldots$ Т..... & $\ldots \ldots \ldots$. & TQ \\
\hline HT06 & $\ldots-\ldots \ldots$ & $\ldots \ldots$. . . & . AA. AGGC. & $\ldots$ G. . . . C & A. ... A. C. . & XQ \\
\hline HT07 & $\ldots-\ldots$ C... & $\ldots \ldots$. $\ldots$ & . . AA. AGGC. & $\ldots$ G.....C & A....A. C. . & $\mathbf{X Q}$ \\
\hline HT08 & $\ldots \ldots \ldots$ & $\ldots \ldots$ C. . & . AA. AGGC. & .. G. A. . C. C & A. ... A. CC. & DFH \\
\hline HT09 & $\ldots-\ldots \ldots$ & $\ldots \ldots$. . . & . AA. A. GC. & $\ldots$ G. . . . C & A. ... A. C. . & $\mathbf{X Q}$ \\
\hline HT10 & $\ldots \ldots \ldots$ & $\ldots \ldots$. . & .. AA. A. GT. & $\ldots$ G...... & A.... A. CC. & DFH \\
\hline HT11 & G....... & $\ldots$. GC. . & T. AAAAG. . . & ..G....C.C & A... T. . . . & TQ \\
\hline HT12 & G. . TC. .. & $\ldots$. . GC. . & T. AAAAG. . . & . G. . . C. C & A... T. . . . & TQ \\
\hline HT13 & .C...... & & . AAAA. ... & $\ldots \ldots \ldots C$ & A. .. TA. C. . & DFH \\
\hline HT14 & $\ldots$ T..... & T...... & . AAAA. ... & $\ldots G \ldots \ldots C$ & A. C. . A. CC. & DFH \\
\hline HT15 & $\ldots \ldots \ldots$ & T....... & . AAAA. . . . & $\ldots$ G. . . . C & A. C. . A. CC. & DFH \\
\hline HT16 & $. C . \ldots \ldots$ & T....... & . . AAAA. . . & $\ldots$ G.....C & A. C. . A. CC. & DFH \\
\hline HT17 & $\ldots \ldots \ldots A$ & T. . . . . & . AAAA. ... & $\ldots$ G. . . C & A. ... AACC. & DFH \\
\hline HT18 & & T....... & . AAAA. ... & $\ldots$ G. . . . C & A. .... AACC. & DFH \\
\hline HT19 & $\ldots \ldots \ldots$ & T.....G. & T. AAAA. ... & $\ldots$ G.....C & A. . . TA. CC. & TQ \\
\hline HT20 & $\ldots \ldots$. $\ldots$ & $\ldots$ & . . AAAA. . . & $\ldots$ G...... & A. ... A. CC. & XQ \\
\hline HT21 & . & . & . AAAA. . . . & . G. . & A. ... A. CC. & $\mathbf{X Q}$ \\
\hline HT22 & ..A.A & T... & . AAAA. ... & . GT. TA. . & A. .... АACCT & TQ \\
\hline HT23 & $\ldots \ldots$ A. A & T. . Т.... & . AAAA. ... & . GT. TA. . & A. .... AACCT & TQ \\
\hline HT24 & $\ldots \ldots \ldots$ G & ... TG. . G. G & . . AAAA. ... & . GT. TA. G. & A. ... A. CCT & TQ \\
\hline HT25 & $\ldots \ldots \ldots$ G. & ... TG. . G. . & . AAAA. ... & . GT. TA. G. & A. ... A. CCT & $\mathbf{T Q}$ \\
\hline HT26 & . & $\ldots$. G. . . & . GAAAA. . . A & GAGT. TA. . . & AA. . TA. CCT & DFH \\
\hline HT27 & $\ldots \ldots \ldots$ & T. T. . G. . G. & . AAAA. . C. & ... T. TAC. . & A. . TT. . CCT & DFH \\
\hline
\end{tabular}

少, 群体间差异均数较高。

同时利用 MEGA2 软件中 Kimura 2-parameter 法, 包括转换 (transition) 与颠换(transversion), 计 算序列间的遗传距离矩阵。完达山地区狍种群内平 均遗传距离为 $1.05 \%$, 小兴安岭地区狍种群内平均 遗传距离为 $1.99 \%$, 大兴安岭地区狍种群内平均遗 传距离为 $2.88 \%$ 。

基于 $\mathrm{NJ}$ 和 $\mathrm{BI}$ 系统发生树分析, 来自不同山系
的样品均未表现出按地理分布形成明显的簇（图 2 和 3), 而缺乏比较明显的, 则按地理单元划分为簇 的地理分布格局 (单倍型分布见表 1 )。

\section{3 讨 论}

物种遗传多样性的高低是评判物种是否能长 期生存的依据, 而衡量一个种群 mtDNA 的遗传多 样性有两个重要指标: 单倍型之间的平均遗传距离 
表 2 狍线粒体 DNA 多样性（种群内）

Tab. 2 MtDNA diversity of roe deer (Within populations)

\begin{tabular}{|c|c|c|c|c|}
\hline \multirow{3}{*}{ 参数 Parameters } & \multicolumn{3}{|c|}{ 种群 Population } & \multirow{3}{*}{ 合计 Total } \\
\hline & 大兴安岭 & 小兴安岭 & 完达山 & \\
\hline & Great Khinghan & Lesser Khinghan & Wandashan Mountains & \\
\hline 序列数 Number of sequences & 12 & 6 & 14 & 32 \\
\hline 单倍型数 Number of haplotype & 11 & 5 & 11 & 27 \\
\hline 突变数 Total number of mutations & 35 & 8 & 38 & 50 \\
\hline 多态位点数 Number of polymorphic sites & 35 & 8 & 38 & 50 \\
\hline 单倍型多样性 Haplotype diversity $(h)$ & $0.985 \pm 0.040$ & $0.956 \pm 0.045$ & $0.933 \pm 0.122$ & $0.978 \pm 0.012$ \\
\hline 核苷酸多样性 \%Nucleotide diversity $(\pi)$ & $2.803 \pm 0.225$ & $1.946 \pm 0.401$ & $1.031 \pm 0.190$ & $2.260 \pm 0.199$ \\
\hline 核苷酸差异多样性 Average number of nucleotide difference & 12.894 & 8.912 & 4.733 & 10.353 \\
\hline$(G+C)$ 含量 $(G+C) \%$ & 33.8 & 33.8 & 34.2 & 33.9 \\
\hline Tajima 检验 Tajima's $D$ & $0.50976^{*}$ & $-1.10307^{*}$ & $1.06909^{*}$ & $-0.61266^{*}$ \\
\hline Fu and $\mathrm{Li}$ 检验 Fu and Li's D & $1.10145^{*}$ & $-0.65097^{*}$ & $1.59817^{* *}$ & $0.11749^{*}$ \\
\hline
\end{tabular}

${ }^{*} P>0.1$, not significant; ${ }^{* *} 0.1>P>0.05$, statistical significant.(Tajima,1989; Fu \& Li,1993)

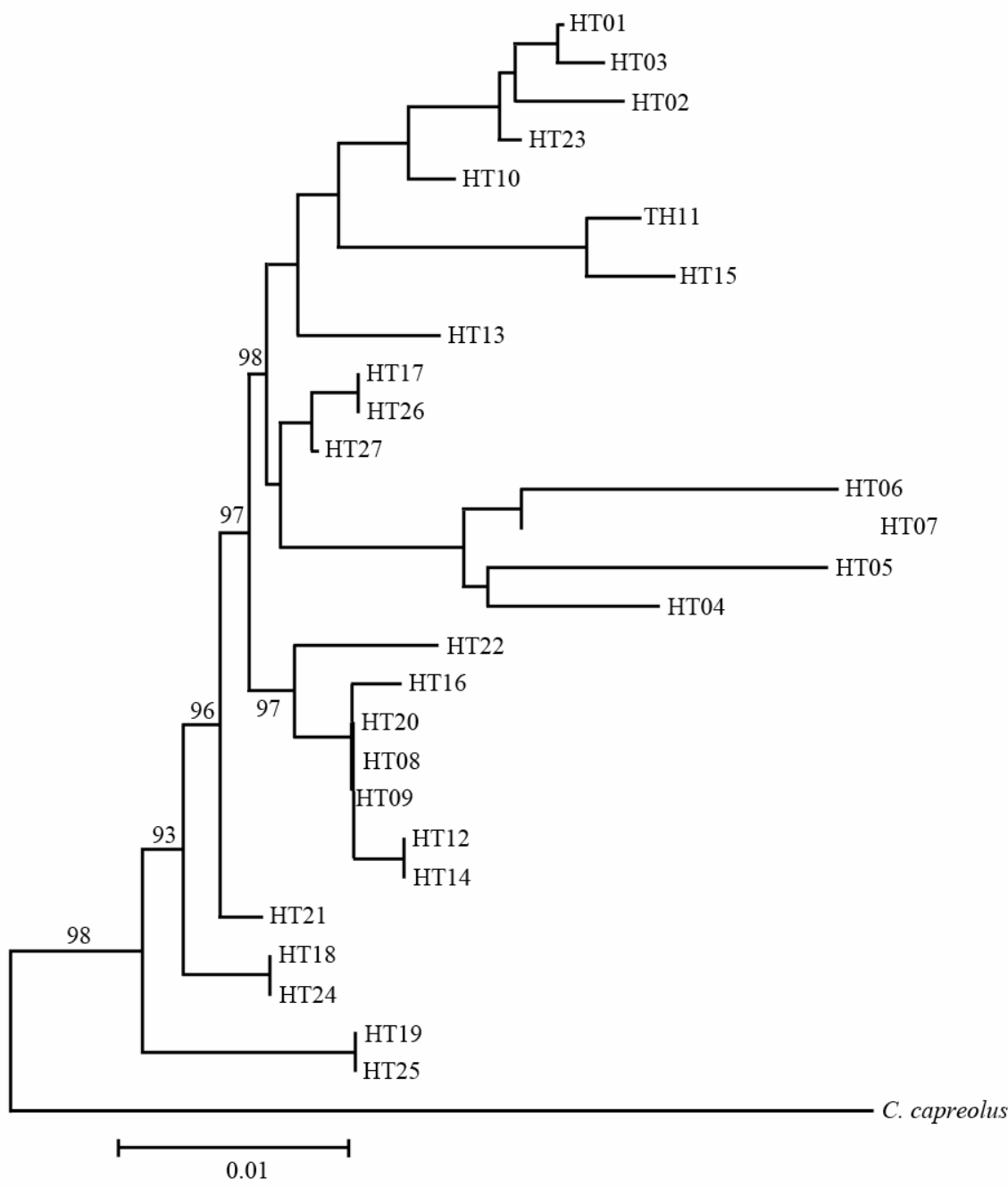

图 2 NJ 法构建的狍 mtDNA 控制区序列的系统发生树

Fig. 2 Phylogenetic relationship of the roe deer mtDNA control region haplotypes constructed by the neighbor-joining method 
表 3 狍线粒体 DNA 多样性（种群间）

Tab. 3 MtDNA diversity of roe deer (Between populations)

\begin{tabular}{|c|c|c|c|}
\hline 参数 Parameters & $\mathrm{XQ}-\mathrm{DFH}$ & $\mathrm{TQ}-\mathrm{XQ}$ & TQ-DFH \\
\hline 种群间核苷酸差异平均数 Average number of nucleotide differences between populations & 8.071 & 11.619 & 10.722 \\
\hline 种群间核苷酸歧异度 Average number of nuc. subs. per site between population (Dxy) & 0.01762 & 0.02537 & 0.02336 \\
\hline 共有的变异位点 Shared Mutations & 7 & 24 & 5 \\
\hline 固定差异位点 Number of fixed differences & 0 & 0 & 0 \\
\hline 种群间的分化水平/每群体间的迁移个体数(基因流) Fst/Nm & $0.12449 / 3.53$ & $0.03182 / 15.33$ & $0.20000 / 2.00$ \\
\hline 地理单元间遗传分化系数/每群体间的迁移个体数 Gamma ST/Nm & $0.10106 / 4.45$ & $0.06362 / 7.36$ & $0.13144 / 3.30$ \\
\hline
\end{tabular}

TQ: 大兴安岭山系种群; XQ: 小兴安岭山系种群; DFH: 完达山山系种群。

TQ:Great Khinghan population; XQ :Lesser Khinghan population; DFH :Wandashan Mountains population.

C. capreolus

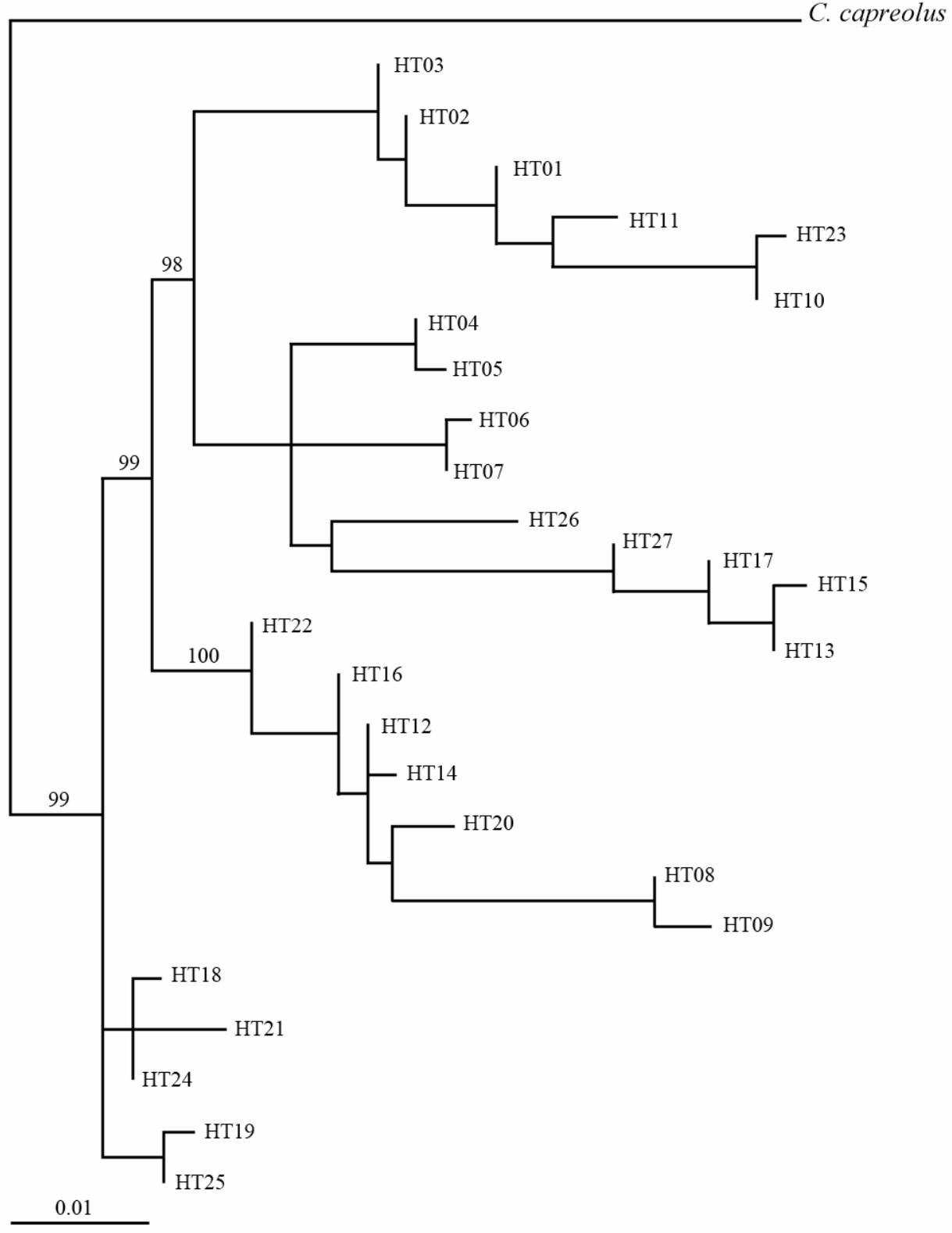

图 3 贝叶斯法构建的狍 mtDNA 控制区序列的系统发生树

Fig. 3 Phylogenetic relationship of the roe deer mtDNA control region haplotypes constructed by the Bayesian method

和核苷酸多态性。由于核苷酸多态性的值计算了各 种 mtDNA 单倍型在群体中所占的比例, 因此在反 
映一个群体的 mtDNA 的多态程度时核苷酸多态性 比单纯的遗传距离平均值要精确, 核苷酸多态性的 值越高, 则说明群体的遗传多样性越高。本研究中 3 个地理单元狍核苷酸多态性在 $1.03 \%-2.80 \%$ 之 间, 平均核苷酸多态性为 $2.26 \%$, 其中大兴安岭狍 种群核苷酸多态性较高为 $2.80 \%$, 这与其他野生动 物相比是较高的, 如非洲花毛羚 (Hippotragus equinus), 其线粒体核苷酸多态性为 1.9\% (Alpers et $\mathrm{al}, 2004$ ), 英国马鹿(Cervus elaphus)的线粒体核苷酸 多态性为 $0.56 \%$ (Hmwe et al, 2006), 中国大陆梅花 鹿(Cervus nippon)种群的线粒体核苷酸多态性为 2.11\% (Liu et al,2003), 从而说明东北地区狍群体 线粒体 DNA 控制区存在着丰富的多态性, 原因可 能是我国东北地区历史上植被一直保存比较完整, 虽然近年来人类活动的干扰使原本连成一片的原 始森林呈现板块状分布, 但是仍然存在适合于狍生 存的环境，不同山系的种群间个体仍能相互迁移， 同时也说明此地区狍没有经历瓶颈效应或建群者 效应。

关于不同山系间的群体遗传结构情况, 我们测 得了 3 个山系种群间的核苷酸歧异度: 大兴安岭与 小兴安岭地理单元种群间的核苷酸歧异度为 $2.54 \%$; 大兴安岭与完达山地理单元种群间的核苷 酸歧异度为 $2.34 \%$; 小兴安岭与完达山地理单元种 群间的核苷酸歧异度为 $1.76 \%$ 。可以看出各地理单

\section{参考文献:}

Adams JR, Kelly BT, Waits LP. 2003. Using faecal DNA sampling and GIS to monitor hybridization between red wolves (Canis rufus) and coyotes (Canis latrans)[J]. Mol Ecol, 12: 2175-2186.

Alpers DL, Van Vuuren BJ, Arctander P, Robinson TJ. 2004. Population genetics of the roan antelope (Hippotragus equinus) with suggestions for conservation [J]. Mol Ecol, 13(7): 1771-1784.

Chen HP, Xiao QZ. 1991. Comparison of winter trophic strategies between red deer and roe deer in Dailing region [J]. Acta Ecol Sin, 11(4): 349-354.[陈化鹏, 萧前柱. 1991. 带岭林区马鹿和狍冬季营养对策 的比较. 生态学报, 11(4): 349-354.]

Excoffier L, Smouse PE. 1992. Analysis of molecular variance inferred from metric distance among DNA restriction data [J]. Genetics, 131: 479-491.

Fu YX,Li WH.1993.Statistical tests of neutrality of mutations[J]. Genetics, 133: 693-709.

Hmwe S, Zachos E, Sale J. 2006. Genetic variability and differentiation in red deer (Cervus elaphus) from Scotland and England [J]. J Zool, 270: 479-487.

Hudson RR, Slantkin M, Maddison WP. 1992. Estimation of levels of gene flow from DNA sequence data[J]. Genetics, 132: 583-589.

Kumar S, Tamura K, Jakobsen IB, Nei M. 2001. MEGA2: Molecular
元间并无显著的遗传分化出现 $(0.145<\Phi$ st $<0.243$, $P>0.05 ; 2.00<N m<15.33)$ 。此外, 从构建的系统树 中, 也可以看出狍种群内的遗传多样性水平较高, 3 个地理单元间没有分别聚为 3 个支系, 而是相互 交错相聚, 说明群体间没有出现显著的分化, 表明 3 个地理群体间的遗传基础比较一致，存在基因流。 这一结果与我们单倍型及其频率、Fst 值、遗传距 离、基因流分析所提示的结果一致。

虽然, 狍不是我国重点保护动物, 但却是重要 的经济兽类, 也是森林肉食动物的重要食物, 具有 重要的生态学和经济意义。近年来, 由于人类活动 （林地开垦、道路修建、居民点扩增、森林砍伐等） 的干扰加剧, 已使其生境遭到不同程度的破坏。因 此, 在加强狍栖息地的保护和修复工作的同时, 对 基因流强度较高的斑块应重点加以保护, 逐渐恢复 片断化狍种群的大小, 以便将能有效地保护狍种群 的遗传多样性。在基因流强度较低的斑块间人为建 立廊道，供种群间个体迁移所用; 有计划地恢复一 些对基因流有重大影响的栖息地。对于无法恢复或 者建立廊道的片断化栖息地，可以根据等位基因的 差异程度，采用人工引种，人为的增加种群间的基 因交流，增大物种的遗传多样性（Wang,1998），也 可以在残留种群间保留一些作为基因流踏脚石的 个体或小种群, 在景观水平上形成斑块种群, 将能 更有效地保护狍种群。

evolutionary genetics analysis software[J]. Bioinformatics, 17(12): 1244-1245.

Liu H, Yang G, Wei FW, Li M, Hu JC. 2003. Sequence variability of the mitochondrial DNA control region and population genetic structure of sika deers (Cervus nippon) in China[J]. Acta Zool Sin, 49(1): 53-60.[刘 海, 杨 光, 魏辅文, 李 明, 胡锦且. 2003. 中国大陆梅花鹿 mtDNA 控制区序列变异及种群遗传结构分析. 动物学报, 49(1): 53-60.]

Ronquist F, Huelsenbeck JP. 2003. MRBAYES 3: Bayesian phylogenetic inference under mixed models [J]. Bioinformatics, 19: 1572-1547.

Randi E, Pierpaoliand A. 1997. Mitochondrial DNA polymorphism in populations of Siberian and European roe deer (Capreolus pygargus and C. capreolus)[J]. Herdity, 80: 429-437.

Rozas J, Rozas R. 2003. Dnasp, DNA polymorphism analysis by the coalescent and other methods[J]. Bioinformatics, 19: 2496-2497.

Sheng HL. 1992. Chinese Deer[M]. Shanghai: East China Normal University Press, 305.[盛和林. 1992. 中国鹿类动物. 上海: 华东师 范大学出版社, 305.]

Swofford DL. 2002. PAUP*: Phylogenetic Analysis Using Parsimony,Version 4 [M]. Sunderland MA: Sinauer Associates.

Tajima F.1989.Statistical method for testing the neutralmutation hypothesis by DNA polymorphism[J]. Genetics, 123: 685-695. 
Teng LW, Liu ZS, Zhang ED, Ma JZ. 2006. Winter bedding site selection by the roe deer(Capreolus capreolus) in Sanjiang Nature Reserve, Heilongjiang Province, China[J]. Zool Res, 27(4): 403-410.[滕丽微, 刘振生, 张恩迪, 马建章. 2006. 黑龙江省三江自然保护区狍对冬 季卧息地的选择. 动物学研究, 27(4): 403-410.]

Thompson JD, Gibson TJ, Plewniak F, Jeanmougin F, Higgins DG. 1997. The Clustal $\mathrm{X}$ windows interface: Flexible strategies for multiple sequence alignment aided by quality analysis tools[J]. Nucleic Acid Res, 24: 4876-4882.

Wang LJ, Hong ML, Xiao XH, Ma JZ. 2005. Morphology and food particles distribution of the digestive tract of roe deer during winter [J]. Acta Theriol Sin, 25(4): 361-366. [王力军, 洪美玲, 肖向红, 马建章. 2005. 狍冬季消化道形态特征及食物颗粒分布. 兽类学报, $25(4)$ : 361-366.]

Wang W. 1998. Molecular phylogenetics and biodiversity conservation[J].
Chn Biodiver, 6(2): 138-142. [王 文. 1998. 分子系统学在生物保护 中的意义. 生物多样性, 6(2): 138-142.]

Xiao CT, Zhang MH, Fu Y, Koh HS. 2007. Mitochondrial DNA distinction of Northeastern China roe deer, Siberian roe deer, and European roe deer, to clarify the taxonomic status of Northeastern China[J]. Biochem Genet, 45(1/2): 93-102.

Yang BT, Ma JZ. 2004. Analyzing the genetic diversity of capreolus in the Northeast by mtDNA D-loopsequence[J]. J Jilin Agricul Univ, 26(6): 672-676. [杨宝田, 马建章. 2004. 东北狍 mtDNA D-loop 序列多态 性分析. 吉林农业大学学报, 26(6): 672-676.]

Zhang MH, Xiao CT, Koh HS. 2005. Taxonomic status of roe deer in Northeastern China based on mitochondrial DNA sequences[J]. Acta Theriol Sin, 25: 14-19. [张明海, 肖朝庭, Koh HS. 2005. 从分子水平 探讨中国东北狍的分类地位. 兽类学报, 25(1): 14-19.]

\section{香港嘉道理农场暨植物园中国项目简介}

香港嘉道理农场暨植物园是香港的一所非牟利机构, 于 1951 年建园, 为有需要的人士提供农业辅助。 本园因适应香港社会的转型, 发展成为环境教育与自然保育中心。致力 “提高大众对人与环境关系的认识, 透过保育和教育，积极改善世界”。本园现推行的计划有野生动植物保育、可持续农业及环境教育等。嘉 道理农场暨植物园于 1998 年 2 月开展华南生物多样性保育计划, 研究队曾在广东、广西、海南等省份 60 多个天然林区进行快速生物多样性评估, 了解当地野生动植物的分布与状况, 及为它们的保育需要排序。 研究队于 2003 年改组为中国项目, 工作范畴亦大大扩展。我们以缓减中国生物多样性丧失及推广可持续 农业为己任，藉保育天然林与极危物种和提倡可持续农业模式，以遏止天然林生态系统受进一步的破坏。 我们与内地林业部门和国内外科研、保育机构合作的主要项目有: 拯救世上最珍稀的猿类海南长臂猿, 并 协助其栖息地的管理; 促进海南全省天然林的有效保育, 特别是全省最大片的热带雨林鸭哥岭和俄贤岭石 灰岩雨林; 推广社区保育项目, 特别是以提倡可持续农业让老百姓了解可持续利用的概念; 保护濒危物种 如闭壳龟等; 研究并发放华南地区野生动植物的分布、现况和贸易的最新讯息。

为培育国内新一代具较强野外能力的保育科研人员, 我们特设嘉道理农场暨植物园奖学金计划, 为硕 士及博士生提供资助和引导。迄今已有 40 位学生获得资助, 其所属院校包括中国科学院的各动物研究所、 植物研究所、北京师范大学、华南农业大学、海南师范大学、广西师范大学等 (排名不分先后)。此外, 我们也为国内科研人员、保育单位提供小型项目资助, 以促进我国保护事业的发展。

联系方法:

嘉道理农场暨植物园中国项目

中国香港特别行政区

香港新界大埔林锦公路

电话: (852) 24837178

传真：（852）2483 1877

电邮：cp@kfbg. org

网站：www. kfbg. org 